J. Lake Sci. (湖泊科学), 2012, 24(2): 178-184

http: //www.jlakes.org. E-mail: jlakes@niglas.ac.cn

(C) 2012 by Journal of Lake Sciences

\title{
三峡工程蓄水对洞庭湖水情的影响格局及其作用机制"
}

\author{
赖锡军, 姜加虎, 黄 群 \\ (中国科学院南京地理与湖泊研究所湖泊与环境国家重点实验室,南京 210008)
}

\begin{abstract}
摘 要: 三峡工程建成投人运行后,汛末蓄水将使坝下河湖水情发生变化,长江中下游秋季来水减少成为常态. 为客观分 析三峡蓄水对洞庭湖水情的影响分量、空间格局及其作用机制,选取三峡工程典型的蓄水过程,运用长江中游江湖耦合 水动力学模型计算了因上游来水变化引起的洞庭湖水情时空变化. 结果表明:1) 三峡汛未蓄水对洞庭湖水位影响具有明 显的“北高南低,东强西弱”的格局, 即东洞庭湖最为显著、南洞庭湖东部和西洞庭湖北部次之,南洞庭湖西部和西洞庭湖 南部最小. 2) 洲滩湿地受蓄水影响最明显的主要为东洞庭湖、南洞庭湖和湖泊洪道两侧的条带状洲滩. 3 ) 三峡蓄水对洞 庭湖水位的影响机制有二:长江干流水位快速消落加速湖泊水体下泄以及削减长江三口分流补给湖泊的水量.
\end{abstract}

关键词: 三峡工程; 蓄水;水情; 淹水历时;水动力学模型;洞庭湖

\section{Pattern of impoundment effects and influencing mechanism of Three Gorges Project on water regime of Lake Dongting}

\section{LAI Xijun, JIANG Jiahu \& HUANG Qun}

(State Key Laboratory of Lake Science and Environment, Nanjing Institute of Geography and Limnology, Chinese Academy of Sciences, Nanjing 210008, P. R. China)

Abstract: With the operation of Three Gorges Project( TGP), water regime of rivers and lakes downstream of the dam changed with the reservoir regulation. The lowering of water level becomes normal after flood season compared with the years before TGP. Here, the water storage of TGP in 2006 was selected as a case to quantitatively investigate the effects of TGP on water regime of Lake Dongting. We applied the coupled hydrodynamic analysis model for the middle Yangtze River to compute the variation of water regime induced by the water storage. During impoundment, the reduction of the water level and discharge are $1.32 \mathrm{~m}$ and $466 \mathrm{~m}^{3} / \mathrm{s}$, respectively, at Chenglingji, the outlet of Lake Dongting. The bottomlands inside the Lake Dongting are exposed ahead of time and the lake area with over 5 inundation days reach to $287 \mathrm{~km}^{2}$. Results also indicate that: 1) the impact of TGP on water regime varied with locations: east Lake Dongting takes the first place, the east of South Lake Dongting and the north of West Lake Dongting second, and the west of South Lake Dongting and the south of West Lake Dongting third. 2) The bottomlands which strongly affected by the impoundment are mainly located at East Lake Dongting, South Lake Dongting and the both sides of flood ways. 3 ) Two influencing mechanisms on water regime are identified: one is the increase of the lake discharge induced by the rapid drawdown of the mainstream of the Yangtze River; the other is the reduction of inflow from the Yangtze River via Sankou distributary channels.

Keywords: Three Gorges Project; impoundment; water regime; inundation duration; hydrodynamic model; Lake Dongting

洞庭湖是我国第二大淡水湖泊,也是长江出三峡后首个与其自然相通的大型湖泊. 它除承接自身流域 来水之外, 还接纳长江三口分流来水,然后经由西、南以及东洞庭湖调蓄后汇人长江, 形成了复杂的江河湖 水系格局. 长江来水的变化直接影响着洞庭湖的水情. 随着三峡工程建成投入运行, 水库的年调节将使三峡 工程对洞庭湖水情的影响成为 “常态”.尤其是汛末蓄水时段,上游来水减少将使洞庭湖水位提前消落,洲滩 湿地出露时间变长. 随着湖泊湿地水文特征的变化湿地生态系统结构发生相应的调整,改变湿地的环境与 生态. 自三峡工程开始论证到如今的建成试运行, 国家启动了诸多重大项目开展三峡工程对坝下游河湖水

* 国家重点基础研究发展计划项目 (2012CB417000)、中国科学院知识创新工程重要方向项目 (KZCX1-YW-08-01) 和国 家自然科学基金项目 (41071021) 联合资助. 2011-07-20 收稿;2011-09-30 收修改稿.赖锡军,男,1977 年生,博士, 副研究员;E-mail:xjlai@ niglas. ac.cn. 
情、泥沙、环境和生态的影响研究 ${ }^{[1-3]}$, 为客观认识三峡工程的影响提供了可靠的资料. 在此期间, 也有大量 有关三峡对洞庭湖影响的相关分析与预测成果公开发表 ${ }^{[4-11]}$, 这些研究加深了人们对三峡工程影响的认识.

自 2003 年三峡工程开始试验性蓄水以来,洞庭湖发生了秋季枯水提前, 持续时间增长的现象, 多次出 现接近历史同期最低水位的枯水 ${ }^{[12]}$. 三峡蓄水对洞庭湖的影响再一次受到了广泛的关注和议论. 相关学者 也从三峡工程自 2003 年蓄水以来的水沙资料人手分析荆江与洞庭湖区的连琐水文效应 ${ }^{[13]}$, 但是由于长江 中游洞庭湖与荆江复杂的交互关系, 水情影响因素众多, 采用历史资料分析的方法难以剔除其它因素的影 响, 难以定量识别三峡工程蓄水运行对洞庭湖水情的影响. 最近作者 ${ }^{[14]}$ 运用针对长江中游河湖特点研制的 江湖耦合的水动力模型(1)分析了汛末蓄水和汛前腾空两个典型时段三峡对湖泊水情和洲滩淹露的影响, 总 体上给出了不同增减下泄流量的影响量级. 本文运用江湖耦合水动力模型, 选取较为典型的 2006 年汛末蓄 水时段,进一步计算了 2006 年三峡工程蓄水实况, 分析了洞庭湖对三峡工程蓄水的响应, 深人分析了三峡 工程蓄水对洞庭湖水情影响的分布格局和作用机制.

\section{1 计算方法及验证}

\section{1 模型方法}

本研究采用针对长江中游江湖水系和水情特点研制的江湖耦合水动力学模型方法. 模型基于一维河网 模型和二维水动力学模型构成, 范围涵盖宜昌至大通段长江中游平原地区的主要江河湖水系, 包括荆江三 口分流河道、洞庭湖四水尾问、汉口仙桃一汉口河段等河道, 其中鄱阳湖和洞庭湖两个大型通江湖泊被概化 成二维计算区域. 该模型细致刻画了洞庭湖的河网水系, 洞庭湖二维计算网格共计 10324 个单元, 10676 节点.

江湖耦合水动力学模型的上游边界条件为长江水系各干支流的人汇流量过程, 下游边界为大通, 给定 多年的水位一流量关系曲线. 因此, 在运用模型进行分析计算时, 只需给定上游宜昌、洞庭湖四水、鄱阳湖五 河、各直接汇人长江的支流来流量和初始条件即可计算出整个区域内部的水位、流量 (湖泊内部为流速) 时 空变化过程. 采用 1998 洪水年和 2006 枯水年的水情资料进行的率定和验证计算表明, 模型结果可靠, 适合 用于三峡工程蓄水对洞庭湖水情影响的评估.

\section{2 计算验证}

洞庭湖湖区在水动力计算中选用了分块的随水深变化的糙率 $n$, 表达式为 $n=n_{0} h^{-1 / 6}$ (式中, $n_{0}$ 为水深 $1 \mathrm{~m}$ 的基础䊁率值, $h$ 为水深). 湖区分洪道、大水面和三种滩地类型共五块给定 $n_{0}$ 值. 洞庭湖湖区各主要站点的 2006 年流量和水位计算结果验证见图 1 , 各站点的 Nash 效率系数 ${ }^{[15]}$ 值都超过 0.9 , 较为准确地模拟了洞庭 湖各个湖区的进出流流量和湖泊水位.

\section{3 三峡工程 2006 年蓄水影响计算}

三峡工程于 2006 年 9 月 20 日 22 时开始启动 $156 \mathrm{~m}$ 蓄水试验, 10 月 27 日三峡水库坝前水位成功达到 $156 \mathrm{~m}$ 高程, 共历时 $37 \mathrm{~d}$. 虽然 2006 年没有蓄水至 $175 \mathrm{~m}$, 但是蓄水调节的出库流量过程和人库流量削减的 量值相当, 而且 2006 年存在两个典型的削峰过程 (图 2), 有助于分析三峡工程蓄水过程对坝下洞庭湖水情 的作用机制.

三峡工程蓄水仅改变了长江下泄流量, 而不影响其它区域水量. 若要识别三峡工程 2006 年蓄水的影响 分量, 需要对比现状 (蓄水) 和不蓄水两种情景下的湖泊水情时空变化信息进行分析. 对于 2006 年蓄水的现 状条件水情, 采用宜昌实测流量边界和其它各边界处实测人流过程输人模型即可得到, 验证结果见 1.2 节. 给定不蓄水情景下的宜昌流量边界条件, 而维持其它边界条件、初始条件和模型参数不变, 即可计算出 与现状条件相对应的 2006 年不蓄水的水情信息. 根据 2006 年长江上游来水的实际情况, 本文以上游 清溪场流量过程作为长江上游的实际来水量过程, 并根据清溪场至宜昌的水流传播时间将其折算到 宜昌站, 作为上游来水过程边界条件.

(1) 中国科学院“三峡工程蓄水运行生态环境影响跟踪评估研究”, 研究报告,2011. 


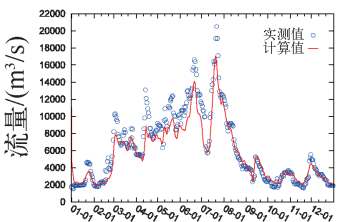

城陵矶

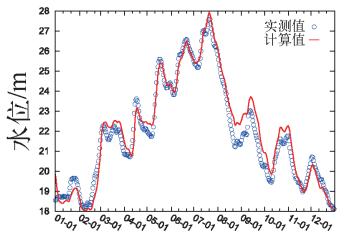

城陵矶

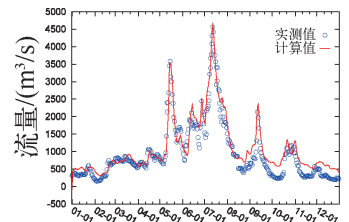

南勗

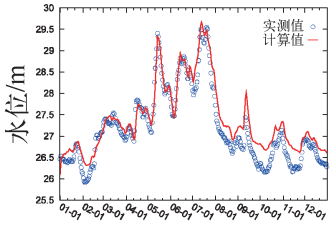

南阻

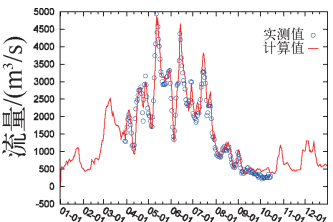

小河咀

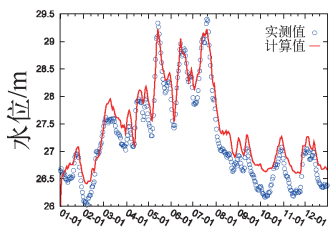

小河咀

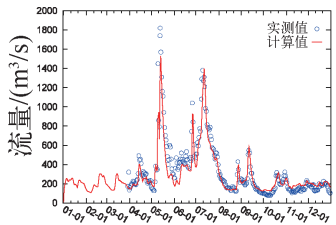

石龟山

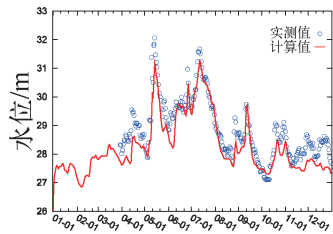

石龟山

图 1 洞庭湖主要站点流量和水位验证

Fig. 1 Comparison of computed and measuredon discharge and water level at Chenglingji, Nanzui, Xiaohezui and Shiguishan stations in Lake Dongting

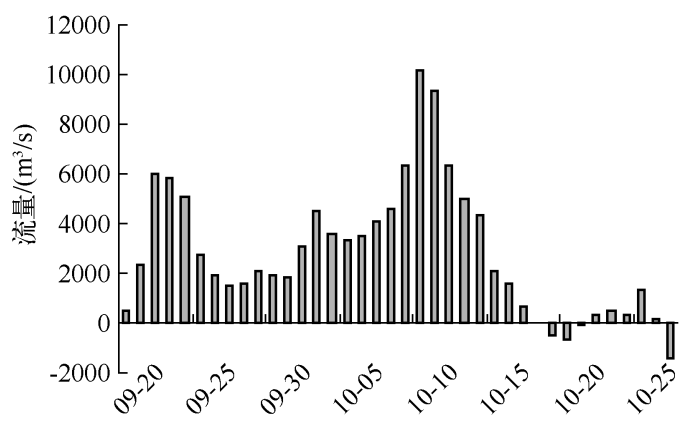

图 2 三峡蓄水减泄流量过程

Fig. 2 Hydrograph of discharge reduction at Yichang due to the impoundment of TGP

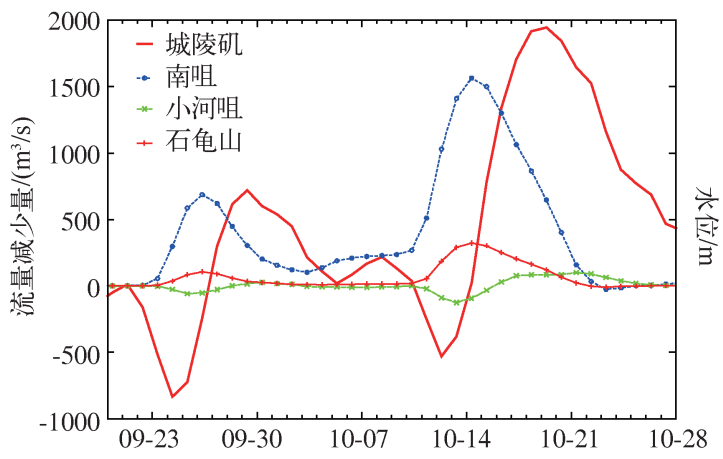

图 3 洞庭湖主要站点流量减少量值过程线

Fig. 3 Hydrograph of discharge reduction at Chenglingji,

Nanzui, Xiaohezui and Shiguishan stations in Lake Dongting

\section{2 三峡工程蓄水对湖泊水情的影响}

\section{1 蓄水引起的湖泊出流流量变化}

洞庭湖各湖区出流流量对蓄水的响应各不相 同(表 1 、图 3 ). 其中城陵矶流量有增有减,最大 流量增幅为 $836 \mathrm{~m}^{3} / \mathrm{s}$, 最大减幅为 $1948 \mathrm{~m}^{3} / \mathrm{s}$, 蓄 水时段内平均降低了 $466 \mathrm{~m}^{3} / \mathrm{s}$; 西洞庭湖北部的 南咀流量在整个蓄水过程中一直比三峡未蓄水情 景时少, 流量最大减少了 $1565 \mathrm{~m}^{3} / \mathrm{s}$, 平均减少了 $420 \mathrm{~m}^{3} / \mathrm{s}$; 小河咀流量平均下降 $5 \mathrm{~m}^{3} / \mathrm{s}$, 但是有两 个明显的流量增加峰值, 最大增加量为 $126 \mathrm{~m}^{3} / \mathrm{s}$ (表 1 ).

\section{2 蓄水引起的水位变化及其分布特征}

蓄水引起的洞庭湖湖区各主要控制站点的水 位降低量值统计表明, 三峡蓄水对洞庭湖水位的 影响具有明显的空间异质性 (表 1). 东洞庭湖所 受影响最大、南洞庭湖东部和西洞庭湖北部次之, 西洞庭湖南部最小, 呈现 “北高南低, 东强西弱” 的基本格局. 洞庭湖东部自北部的城陵矶到南部 的湘阴水文站,影响逐渐递减. 在蓄水影响时间段 内, 城陵矶、鹿角、营田、湘阴站点平均水位降低值 分别为 $1.32 、 1.16 、 0.99$ 和 $0.77 \mathrm{~m}$; 西洞庭湖北部 的石龟山和南咀分别降低 $0.55 \mathrm{~m}$ 和 $0.32 \mathrm{~m}$; 西洞 庭湖西南部的小河咀和周文庙站则分别降低 $0.18 \mathrm{~m}$ 和 $0.09 \mathrm{~m}$, 显著小于其它站点; 南部的资水 尾问沙头站水位降低 $0.12 \mathrm{~m}$, 影响也较小. 10 月 13 日洞庭湖全湖的水位降低量值分布, 能很好地反映 这一空间格局特征(图 4). 
表 1 洞庭湖各站水位和流量变化统计 *

Tab. 1 The effects of TGP water storage on water stage and discharge at main stations of Lake Dongting

\begin{tabular}{|c|c|c|c|c|c|c|}
\hline \multirow[b]{2}{*}{ 站点 } & \multicolumn{3}{|c|}{ 水位削减 } & \multicolumn{3}{|c|}{ 流量变化 } \\
\hline & $\begin{array}{c}\text { 平均值/ } \\
\mathrm{m}\end{array}$ & $\begin{array}{c}\text { 最大值/ } \\
\mathrm{m}\end{array}$ & $\begin{array}{c}\text { 最大值 } \\
\text { 发生日期 }\end{array}$ & $\begin{array}{l}\text { 平均值/ } \\
\left(\mathrm{m}^{3} / \mathrm{s}\right)\end{array}$ & $\begin{array}{l}\text { 最大值/ } \\
\left(\mathrm{m}^{3} / \mathrm{s}\right)\end{array}$ & $\begin{array}{c}\text { 最大值 } \\
\text { 发生日期 }\end{array}$ \\
\hline 宜昌 & 1.16 & 3.72 & $10-10$ & 2786 & 10200 & $10-10$ \\
\hline 城陵矶 & 1.32 & 2.73 & $10-13$ & 466 & $1948(-836)$ & $10-19(09-24)$ \\
\hline 鹿角 & 1.16 & 2.33 & $10-14$ & - & - & - \\
\hline 营田 & 0.99 & 2.03 & $10-16$ & - & - & - \\
\hline 湘阴 & 0.77 & 1.74 & $10-17$ & - & - & - \\
\hline 沙头 & 0.12 & 0.37 & $10-17$ & - & - & - \\
\hline 石龟山 & 0.55 & 2.00 & $10-14$ & 68 & 323 & $10-14$ \\
\hline 南咀 & 0.32 & 1.14 & $10-14$ & 420 & 1565 & $10-14$ \\
\hline 小河咀 & 0.18 & 0.57 & $10-16$ & 5 & $100(-126)$ & $10-21(10-13)$ \\
\hline 周文庙 & 0.09 & 0.32 & $10-16$ & - & - & - \\
\hline
\end{tabular}

* 流量变化数值正数表示流量减少,负数表示流量增加; 城陵矶站和小河咀流量变化增减波动明显,最大增幅和减幅分 别列于表中.

从水位变化的空间格局不难发现: 与长江距离 越近、水力联系越紧密的水域受长江的影响越显著 (表 1、图 4). 东洞庭湖和南洞庭湖的东部有洪道相 连, 水流贯通, 因此长江干流水位快速消落可以较快 地传播至南部的湖区. 西洞庭湖北部因承接长江三 口来水影响较大, 南洞庭湖大部和西洞庭湖则因洲 滩发育较好, 水力连通性不是很好, 使其受三峡蓄水 的影响要小于其它湖区.

\section{3 蓄水引起的洲滩湿地淹水历时变化}

洞庭湖水位降低使得洲滩水文发生一系列变 化, 最为直接的是洲滩湿地出露时间增长, 改变湿地 水文特性. 本文以淹水历时为指标, 说明三峡蓄水对 洞庭湖湿地的影响范围和程度. 洞庭湖湿地淹水历 时和蓄水引起变化的空间格局表明, 各湖区水体较 为独立, 东洞庭湖水域较大, 也较为完整 (图 5 ). 2006 年汛末蓄水影响主要集中于开敞水域周边, 如 东洞庭湖、南洞庭湖的横岭湖和主要洪道的两侧洲

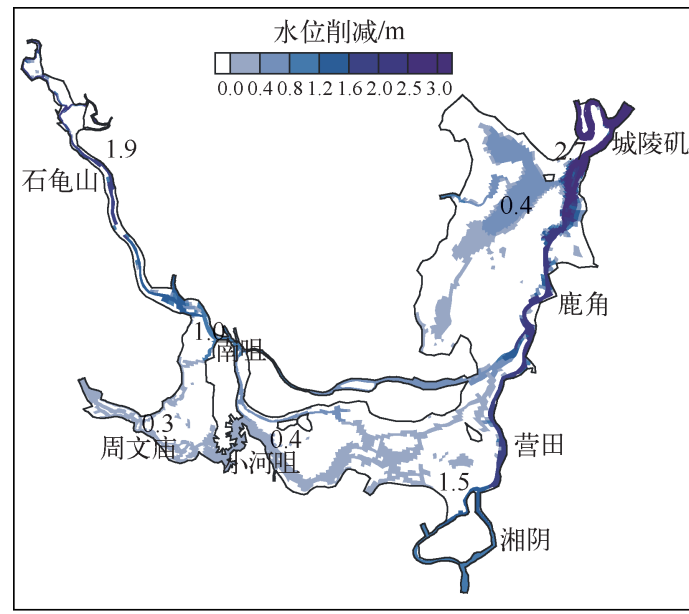

图 4 洞庭湖水位削减空间格局 (10月 13 日)

Fig. 4 Contour map of water stage reductions in Lake Dongting (13rd October) 滩; 而东洞庭湖的漉湖等相对独立的水体没有在计 算中得以体现.

根据淹没天数变化的不同量级, 对湖泊面积的变化进行了统计. 在蓄水时段内, 淹没减少天数 $>15 \mathrm{~d}$ 的 约 $100 \mathrm{~km}^{2}$, 主要分布在东洞庭湖的开敞湖面; 淹没减少天数为 $10 \sim 15 \mathrm{~d}$ 的主要位于东、南洞庭湖, 面积为 $81 \mathrm{~km}^{2}$; 而淹没减少天数为 $5 \sim 10 \mathrm{~d}$ 和 $<5 \mathrm{~d}$ 的分别为 $106 \mathrm{~km}^{2}$ 和 $72 \mathrm{~km}^{2}$, 这些区域主要位于湖泊洪道两侧的 条带状洲滩.

\section{3 三峡工程蓄水的影响过程及作用机制分析}

\section{1 对流量的影响过程}

城陵矶是洞庭湖与长江的汇流口, 城陵矶出口流量过程在三峡的影响下, 既有减少也有增加 (图 3 ). 对 应三峡工程每拦截一次洪峰, 城陵矶出口流量都形成一个明显的流量先增加后减少的过程, 而不是简单的 

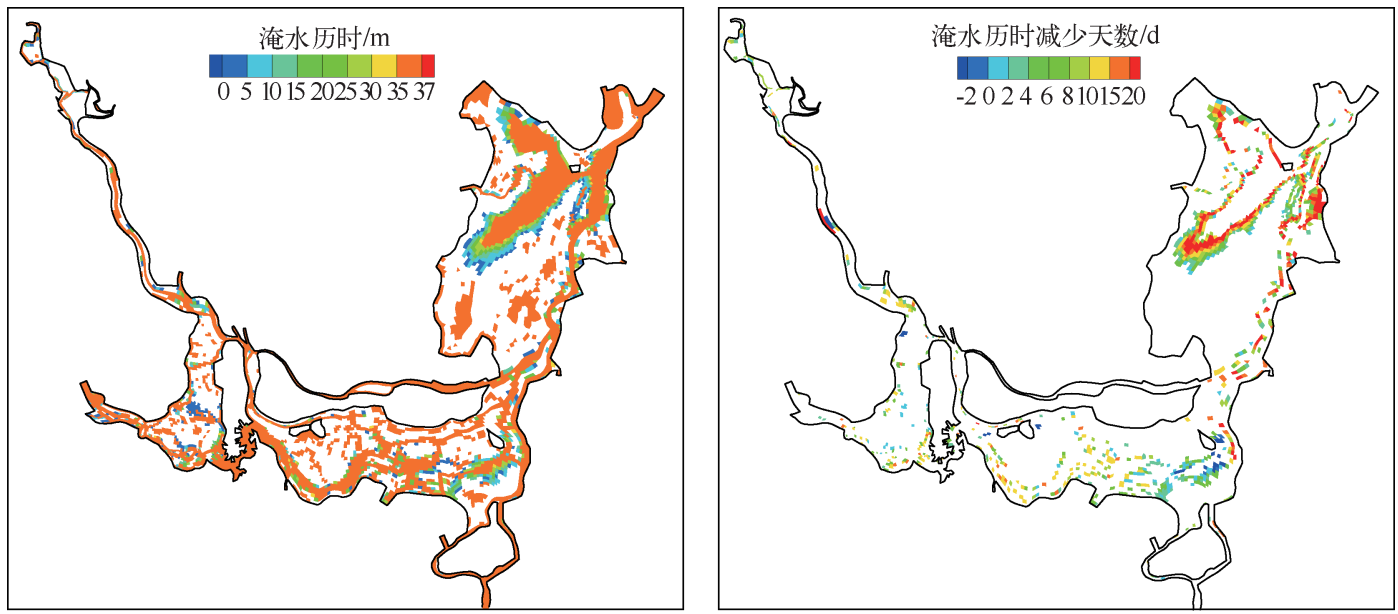

图 5 洞庭湖淹水历时及其变化格局

Fig. 5 Contour map of inundation days and reduced days of Lake Dongting

出口流量增加或是减少. 在蓄水期间, 流量经历了两次明显的先增后减的规律性波动. 对第二次流量波动, 流量增加和减少峰出现时间分别为 10 月 12 日和 10 月 19 日.

西洞庭湖北部出口南咀和松澧虎洪道石龟山站流量过程对三峡蓄水的响应基本一致, 只是石龟山减少 的量值偏小. 对比可以看出, 三峡截流流量和南咀 (石龟山) 流量减少量值的过程线峰型一致, 只是相位滞 后,其最大影响峰值出现日期为 10 月 14 日(图 2、图 3).

对位于西洞庭南部出口的小河咀, 其流量降低值过程线与北部出口的南咀完全不同, 但是和城陵矶出 口流量变化特征较为相似,流量出现规律性的先增后减的波动. 小河咀流量降低值过程线有两个明显的谷 值, 即有明显的流量增加, 其峰现日期分别为 9 月 25 日和 10 月 13 日, 早于南咀流量降低峰现日期 $1 \mathrm{~d}$.

\section{2 对水位的影响过程}

水位削减的量值时间过程线可看出有两个较为明显的峰值 (图 6), 和三峡拦蓄了上游两次较大洪峰一 致. 第二次拦截的洪峰流量 $>10000 \mathrm{~m}^{3} / \mathrm{s}$, 洞庭湖水位也因此失去了此次洪峰补水的机会. 水位持续保持较

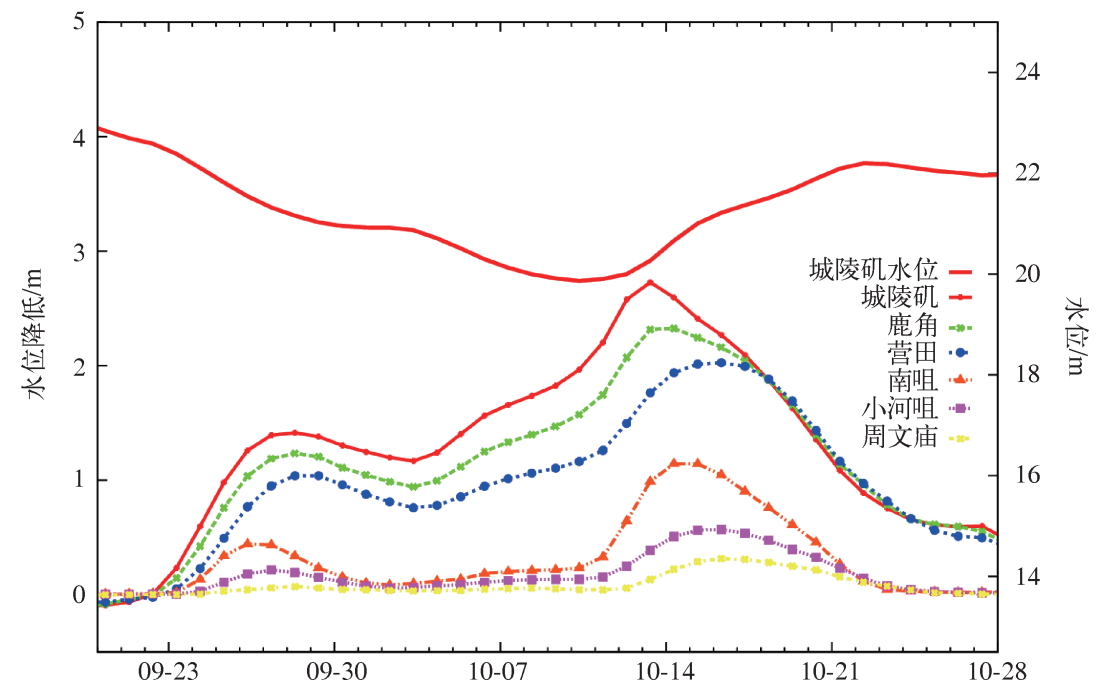

图 6 洞庭湖主要站点水位降低值过程线

Fig. 6 Hydrograph of stage reduction at main stations of Lake Dongting 
低水平,使得洞庭湖水位与未蓄水条件相比差距达到了最大,其中城陵矶站于 10 月 13 日达到了最大的 $2.73 \mathrm{~m}$. 鹿角、营田和湘阴也于随后的 14 日、16 日和 17 日达到最大值. 西洞庭湖北部承接长江来水, 受影响 较快,石龟山和南咀站均于 14 日达到了最大值. 而西洞庭湖的北部影响则有明显滞后, 小河咀和周文庙均 于 16 日才达到最大.

\section{3 湖泊水位降低的作用机制分析}

首先来考察西洞庭湖北部湖区, 从南咀和石龟山的水位和流量所受的影响来看, 水位和流量的峰现时 间同步, 说明该区域湖泊水位的降低直接来自于来水量的减少. 这也和我们通常认识的西洞庭湖北部的洪 道主要起着接纳、输送长江三口来水是一致的. 为此, 可以断定西洞庭湖北部湖区主要体现了三峡蓄水减少 来水的影响,即蓄水使干流水位降低,三口分流量较蓄水期减少.

西洞庭湖南部湖区的水位与出流量的变化则体现了三峡蓄水对湖泊水情影响的另一个方面. 从小河咀 水位和流量的变化过程发现,对应于三峡的蓄水过程, 湖泊出流量先增后减, 湖泊水位则持续减小, 水位所 受影响缓慢递增, 直至达到一个峰值; 其峰值出现日期要迟于流量增加最大的日期, 而与流量变化为零的日 期一致,这说明出口流量的增加加速了湖泊水位的下降. 在枯水期, 西洞庭湖洲滩多数出露( 尤其是 2006 年 夏季枯水使湖泊底水位较低), 南部目平湖和沅水洪道与北部的松澧虎洪道水体主要通过窄小的洪道沟通, 水力连通性不好, 南部形成了较为独立的水体. 长江三口来水只有很少一部份经窄小渠道向南流人南部湖 区. 小河咀和南咀出流与赤山岛东侧洪道处汇合, 汇流后可能直接进人东南湖或者经由北部的赤硈洪道直 达东部. 南咀受蓄水截流的影响较早, 来水减少使水位的提前消落, 出口水位的下降, 使南部出流洪道水力 坡降增大. 以 10 月 13 日为例, 在蓄水条件下, 南咀比小河咀高出 $0.08 \mathrm{~m}$, 而未蓄水的条件下则高达 $0.68 \mathrm{~m}$. 大水力坡降促使出口流量加大, 加速湖水位下降. 经过一段时间调整后, 湖水容积减少, 水力关系趋稳, 流量 逐步回调, 反而比未蓄水情景要略有减少. 西洞庭湖南部水情变化表明, 三峡蓄水可通过出口处水位的快速 下降, 拉抬水力坡降, 加大湖泊泄流量, 从而降低湖泊水位. 西洞庭湖南部水位的降低正好体现了三峡蓄水 对湖泊水情的这一影响机制.

城陵矶出口流量反映两种机制的综合作用. 它既体现了湖口水力坡降提升增加湖泊泄量、加快湖泊排 水的作用, 又体现了三峡蓄水减少对湖泊补水的作用. 洞庭湖通过三口河道接纳长江来水, 经河湖调蓄后, 在城陵矶处汇人长江. 长江三口来水经由河网传输至洞庭湖需要经历较长的历程. 在本次蓄水的水力条件 下, 三峡蓄水使得长江三口来水的减少在城陵矶出口体现出来需要经历 $4 \sim 6 \mathrm{~d}$, 而经由荆江干流传播至洞 庭湖仅需 $2 \sim 3 \mathrm{~d}$. 干流水位的快速消落使得洞庭湖出口水力坡降在三口来水还没影响到东洞庭湖时快速加 大, 洞庭湖出流流量增加. 之后, 在三口河道来水减少和湖水快速排空的作用下, 流量又随之下降. 南咀反映 长江来水的主要变化, 对比城陵矶和南咀出口流量在蓄水期间的平均减少量, 可以发现城陵矶仅略高于南 咀. 如果加上藕池东支直接流人东洞庭湖的水量减少值(藕池分流共减少 $76 \mathrm{~m}^{3} / \mathrm{s}$ ), 水量变化基本吻合.

综上所述,在洞庭湖和长江即时的水动力交互作用下, 三峡蓄水使城陵矶出口流量呈有规律的增减变 化, 湖泊水位提前消落. 它对洞庭湖水位的影响通过两种机制起作用:一是长江干流的水位快速下降使湖泊 出流口水力坡降变大, 洞庭湖出流流量增加, 湖泊水位下降; 二是长江三口分流减少使得湖区水量补给变 少,湖泊水位下降.

\section{4 结论}

本文采用江湖耦合的水动力学方法研究了三峡工程改变上游来水过程对洞庭湖湖泊水位格局和出湖 流量过程的影响,结果可帮助准确认识三峡工程对洞庭湖水情影响的空间格局和作用机制.

1) 2006 年三峡工程蓄水对洞庭湖水情影响较大,致使东洞庭湖的城陵矶、南洞庭湖东部的营田、西洞 庭湖北部出口的南咀和西洞庭湖南部出口的小河咀水位分别平均下降 $1.32 、 0.99 、 0.32$ 和 $0.18 \mathrm{~m}$; 城陵矶 出口流量平均减少 $466 \mathrm{~m}^{3} / \mathrm{s}$; 洲滩湿地提前出露, 三峡工程调节使出露天数变长多于 $5 \mathrm{~d}$ 的面积达 $287 \mathrm{~km}^{2}$, 占洞庭湖面积 $\left(2625 \mathrm{~km}^{2}\right)$ 的 $11 \%$.

2) 三峡汛末蓄水对洞庭湖湖区各水域影响具有明显空间异质性, 呈现 “北高南低, 东强西弱” 的格局. 其中东洞庭湖受长江影响最为显著, 南洞庭湖东部和西洞庭湖北部次之, 南洞庭湖西部和西洞庭湖南部 
最小.

3) 湖泊水位下降使洞庭湖洲滩湿地提前出露, 减少淹没历时可使洞庭湖低位滩地植被提前萌发,植被 带向下推移.受蓄水影响较大的洲滩主要位于东洞庭湖的开敞水域、南洞庭湖和洪道两侧.

4) 三峡蓄水对洞庭湖水位的影响通过两种机制起作用:一是长江干流的水位快速下降使湖泊出流口水 力坡降变大, 洞庭湖水体下泄加速, 湖泊水位下降;二是长江三口分流减少使得湖区水量补给变少, 湖泊水 位下降.

对于长期效应的研究,需要进一步综合三峡工程引起的上游来水来沙变化对下游河道和湖泊演变研究 来开展.

\section{5 参考文献}

[ 1 ] 长江水利委员会. 三峡工程生态环境影响研究. 武汉: 湖北科学技术出版社, 1997: 10.

[2 ] 兴培民, 蔡述明, 朱海虹等. 三峡工程与长江中游湖泊地环境. 北京: 科学出版社, 1994: 8.

[ 3 ] 黄真理, 吴炳方, 敖良桂. 三峡工程生态与环境监测系统研究. 北京: 科学出版社, 2006: 9.

[ 4 ] 洪 林, 董否华, 李文哲. 三峡工程建库后对洞庭湖水位、泥沙和水质的影响分析. 中国水利, 2007,(6): 13-14.

[ 5 ] 李 倩, 曾光明, 黄国和等. 三峡工程对洞庭湖水力梯度及其湿地植物生长的影响. 安全与环境学报, 2005,5 (1) : 12-15.

[6 ] 贺清云, 朱 翔. 三峡工程建设背景下的洞庭湖区治水方略探讨. 地理研究, 2003, 22(2) : 160-168.

[ 7 ] 林秉南, 周建军. 利用三峡枢纽下泄“清水”改善洞庭湖和荆江的防洪局面. 三峡工程建设, 2003, (12): 4-6.

[8] 邹邵林, 刘晓清. 三峡工程对洞庭湖区滩地出露天数的影响. 长江流域资源与环境, 2000, 9(2): 254-259.

[ 9 ] 王祥三, 李大美. 用灰色系统预测模型预测三峡工程对洞庭湖区洲滩面积的影响. 湖泊科学, 1998, 10 (4): $87-90$.

１10］王祥三, 戴裕海. 水动力学法预测三峡工程对洞庭湖洲滩的影响. 长江流域资源与环境, 1997, 6(3) : 277-282.

１11］姜加虎，黄 群. 三峡工程对洞庭湖水位影响研究. 长江流域资源与环境, 1996, 5(4) : 367-374.

[12] 徐俊杰, 何 青, 刘 红等. 2006 年长江特枯径流特征及其原因初探. 长江流域资源与环境, 2008, 17(5): 716722.

[13] 李景保, 常 疆, 吕殿青等. 三峡水库调度运行初期荆江与洞庭湖区的水文效应. 地理学报, 2009, 64 (11): 1342-1352.

[14] 赖锡军, 姜加虎, 黄 群. 三峡水库调节典型时段对洞庭湖湿地水情特征的影响. 长江流域资源与环境, 2011, $20(2): 167-172$.

[15] Nash JE, Sutcliffe JV. River flow forecasting through conceptual model. J Hydrol, 1970, 10(3) : 282-290. 